\title{
Publisher Correction: Cardiac involvement in the long-term implications of COVID-19
}

\author{
Benjamin A. Satterfield (1D, Deepak L. Bhatt $(\mathbb{D})$ and Bernard J. Gersh $(\mathbb{D}$
}

Correction to: Nature Reviews Cardiology https://doi.org/10.1038/s41569-021-00631-3, published online 22 October 2021.

In the version of this article originally published online, Deepak L. Bhatt's declaration of competing interests was omitted. This error has been corrected in the HTML, PDF and print versions of the manuscript.

https://doi.org/10.1038/s41569-021-00641-1 I Published online 1 November 2021

(c) Springer Nature Limited 2021 